\title{
Major detachment of aortic prosthetic valves
}

\author{
George C. Sutton and John E. C. Wright \\ From Brompton Hospital, London S.W.3
}

The clinical and investigatory findings in five instances of major detachment of an aortic valve prosthesis in four patients are described. This situation was associated with auscultatory and peripheral signs of aortic regurgitation and, in addition, a mid-diastolic murmur in the mitral area. From the haemodynamic and operative findings it was postulated that, in addition to severe aortic regurgitation, disturbance of mitral valve function occurred both in systole and diastole caused by the pivoting of the prosthesis attached to the base of the aortic leaflet of the mitral valve. Cardiac fluoroscopy confirmed the diagnosis.

Major detachment of a prosthetic valve is an unusual, but life-threatening, complication of valve replacement surgery. Recognition of such an event must be swift and treatment rapid, though corrective surgery may be associated with a high mortality.

Sudden disruption of cardiac valves produces unusual clinical findings based on gross alteration in haemodynamics without the normal adaptive processes having time to occur. These are well described in aortic valve regurgitation (Meadows et al., 1963; Rees et al., 1964; Wigle and Labrosse, 1965) and in mitral valve regurgitation (Roberts, Braunwald, and Morrow, 1966; Raftery, Oakley, and Goodwin, 1966).

This report concerns the findings in patients in whom an aortic prosthetic valve had rapidly become detached for more than 50 per cent of its circumference. The resultant alteration in haemodynamics produced a characteristic pattern described below in four patients, in one of whom the prosthesis became detached on two occasions.

\section{Case reports}

Case I, aged 55 This patient had severe aortic stenosis with regurgitation. At operation, the aortic valve was heavily calcified and conspicuous post-stenotic dilatation of the aorta was present. After valve excision, a No. I2 Starr-Edwards prosthesis was inserted using multiple interrupted sutures. His post-operative course was uneventful and no aortic diastolic murmur was audible on discharge. Three months later, he was readmitted with a two-day history of dyspnoea. Blood pressure was $130 / 40 \mathrm{~mm}$. Hg; he had sinus tachycardia and a sharp arterial pulse. There was an ejection systolic murmur and early diastolic murmur at the left sternal edge, in addition to Received 21 October 1969. opening and closing sounds of the Starr-Edwards valve. No comment was made on auscultation of the mitral area. Chest $x$-ray showed considerable increase in cardiac silhouette, and in view of this cardiac catheterization was carried out. Screening showed pivotal movement of the prosthesis and severe aortic regurgitation was confirmed by aortography. The mean right atrial pressure was raised with a dominant systolic collapse, and right atrial angiography showed a paracardiac opacity.

At reoperation, the prosthesis was found to be detached for three-quarters of its circumference, with the stitches intact, but torn out of the heart. The valve was attached at the non-coronary sinus and the prosthesis was able to pivot freely in a hinge-like movement. A fresh prosthesis was inserted, but the patient died in the post-operative period with a low cardiac output.

There was considerable paracardiac haematoma found at operation, accounting for the large cardiac silhouette. Necropsy showed a normal mitral valve.

Case 2, aged 52 This patient had severe aortic valve stenosis. At operation, the aortic valve was heavily calcified and post-stenotic dilatation of the aorta was present. The valve was excised and a No. 9 Starr-Edwards prosthesis inserted using multiple interrupted mattress sutures. No aortic diastolic murmur was audible on discharge after an uneventful post-operative course. He was readmitted three months later after an attack of dyspnoea on the night before admission with a one-week history of ankle swelling. On examination, the blood pressure was $100 / 55 \mathrm{~mm}$. $\mathrm{Hg}$ with a sinus tachycardia and a sharp arterial pulse; the venous pressure was raised and there was peripheral oedema. There was an ejection systolic murmur and a soft early diastolic murmur at the left sternal edge. In the mitral area, there was a loud mid-diastolic murmur (Fig. I). Chest $x$-ray showed an unchanged heart size compared with the post-operative film, but there was dila- 


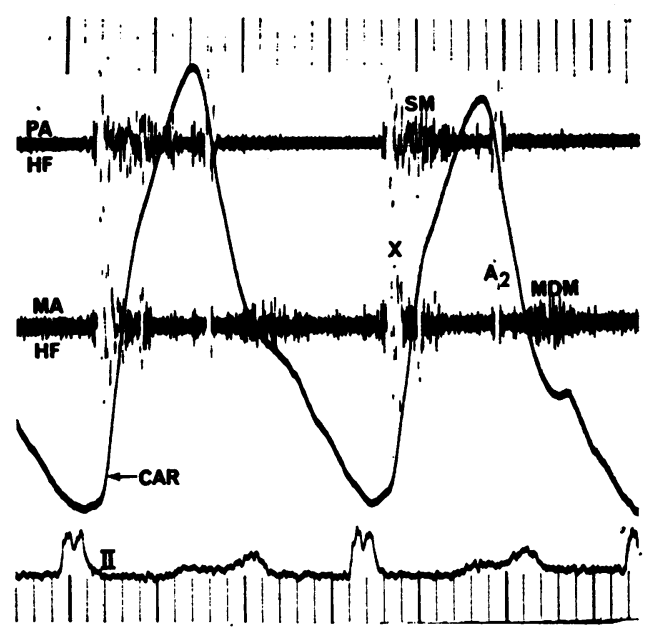

FIG. I Simultaneous high-frequency $(H F)$ phonocardiograms from pulmonary area $(P A)$ and mitral area $(M A)$ showing mid-diastolic murmur (MDM) in MA. Starr-Edwards valve opening sound $(X)$ and closing sound $\left(A_{2}\right)$ are shown together with an ejection systolic murmur (SM). CAR = indirect carotid artery tracing; II = lead II of electrocardiogram. Time-markers $0.04 \mathrm{sec}$.

tation of the upper lobe pulmonary veins and small bilateral pleural effusions. Screening confirmed pivotal movement of the prosthesis.

At reoperation, the prosthesis was found to be two-thirds detached. The stitches had pulled out of the heart, the remaining area of the attachment being the non-coronary sinus region, so that the

FIG. 2 Operative pressure recordings showing non-equilibration of aortic and left ventricular $(L V)$ pressures in diastole; tall systolic waves in left atrial ( $L A$ ) pressure; and absence of diastolic gradient between the left atrium $(L A)$ and left ventricle $(L V)$.
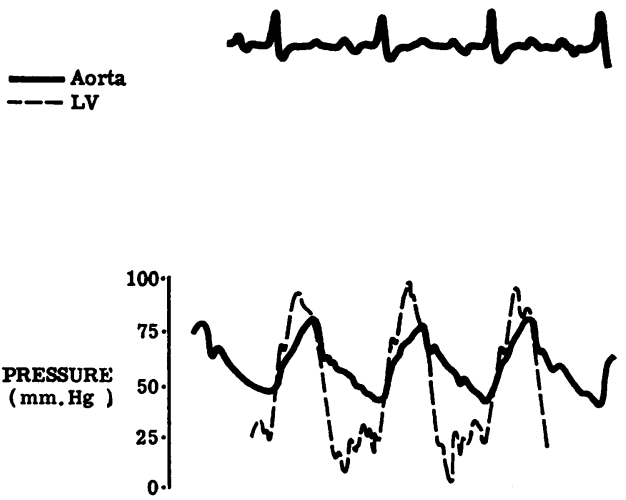

valve was free to pivot through about $60^{\circ}$. The prosthesis was removed and a $2.5 \mathrm{~cm}$. homograft inserted. The mitral valve appeared normal on inspection through the aortotomy. Simultaneous pressures were taken from the left atrium, left ventricle, and aorta before bypass (Fig. 2). These records did not show any diastolic gradient between the left atrium and ventricle, but there was a $45 \mathrm{~mm}$. $\mathrm{Hg}$ systolic wave in the left atrial pressure tracing. There was no equilibration of aortic and left ventricular diastolic pressures, as may be seen in severe aortic regurgitation (Meadows et al., 1963).

The patient was discharged free of murmurs one month later and has remained well one year later.

Case 3, aged 58 This patient had severe aortic stenosis with slight aortic regurgitation. At operation, the valve was heavily calcified and poststenotic dilatation of the aorta was present. The valve was excised and a $2.5 \mathrm{~cm}$. homograft inserted. The post-operative course was uneventful. An aortic diastolic murmur was first noted Io months later, and 16 months after operation he was admitted in heart failure with the features of severe aortic regurgitation.

Reoperation revealed that the aortic annulus had dilated $(2.75 \mathrm{~cm}$.) and the homograft cusps, though normal in appearance, were no longer competent. A No. II Starr-Edwards prosthesis was inserted using interrupted mattress sutures. Three weeks later an aortic diastolic murmur was noted. Screening at this time showed normal movement of the prosthesis without any pivoting. Two weeks later he developed a pyrexia and a corynebacterium was isolated from blood cultures. After intensive treatment with streptomycin and cephaloridine for 8 weeks he improved and was discharged symptom free, with an aortic diastolic murmur, but without clinical evidence of severe aortic regurgitation.

Shortly afterwards he was readmitted with severe left ventricular failure and complete heart block. On auscultation, there were ejection systolic and early diastolic murmurs at the left

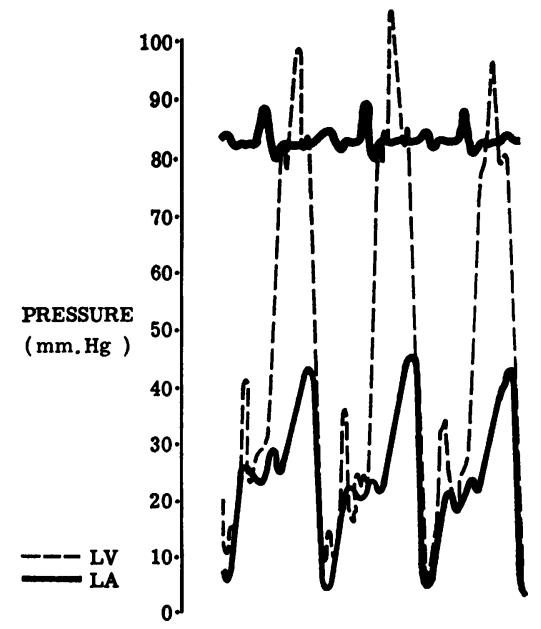


sternal edge and a mid-diastolic murmur in the mitral area. Screening now showed conspicuous pivotal movement of the prosthesis (Fig. 3).

His condition deteriorated rapidly and he died. At necropsy, vegetations were seen on the prosthesis. The prosthesis was attached only at the non-coronary sinus area, and free rocking on this hinge could be easily reproduced (Fig. 4-6). The mitral valve was normal.

Case 4, aged 50 This patient had severe aortic regurgitation. At operation, the valve was bicuspid with a ragged calcified central opening; there was conspicuous post-stenotic dilatation of the aorta. After valve excision, a $3 \mathrm{~cm}$. homograft was inserted. By the second post-operative week severe aortic regurgitation had again appeared and reoperation was decided upon. The leaflets of the homograft were seen to be prolapsing through the centre of the graft. The graft was excised and a No. II Starr-Edwards prosthesis inserted using interrupted sutures. He recovered slowly, with an episode of confusion and rightsided neurological deficit.

Four months later, he was readmitted with jaundice, thought to be due to serum hepatitis,

FIG. 3 Individual frames taken from the cine film (left anterior oblique position) of a detached aortic prosthesis. Frames show position in systole (above) and diastole (below) demonstrating approximately $60^{\circ}$ of rotation in this plane.
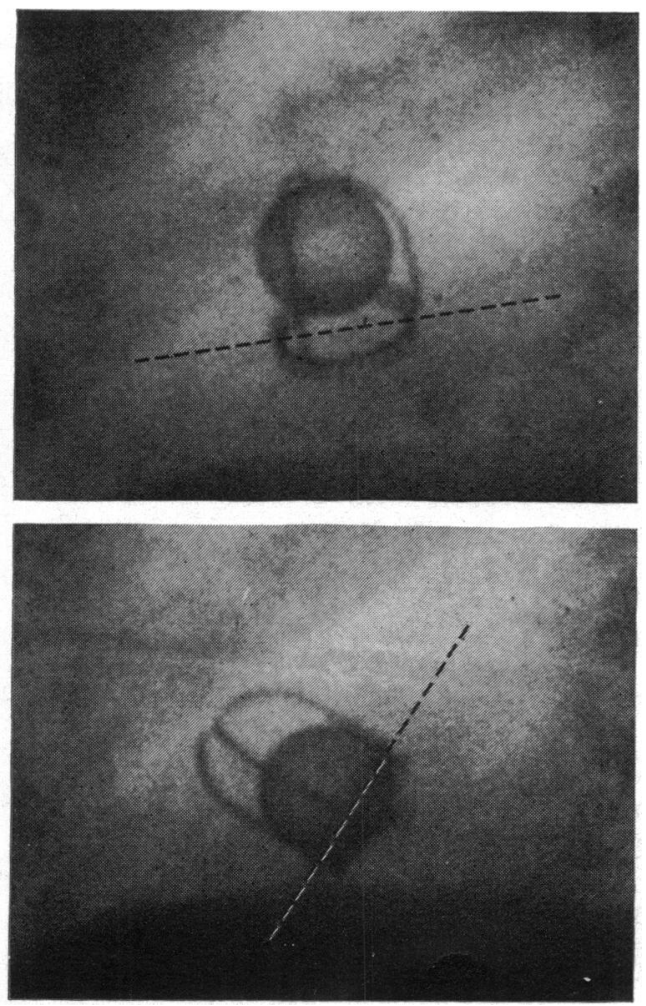

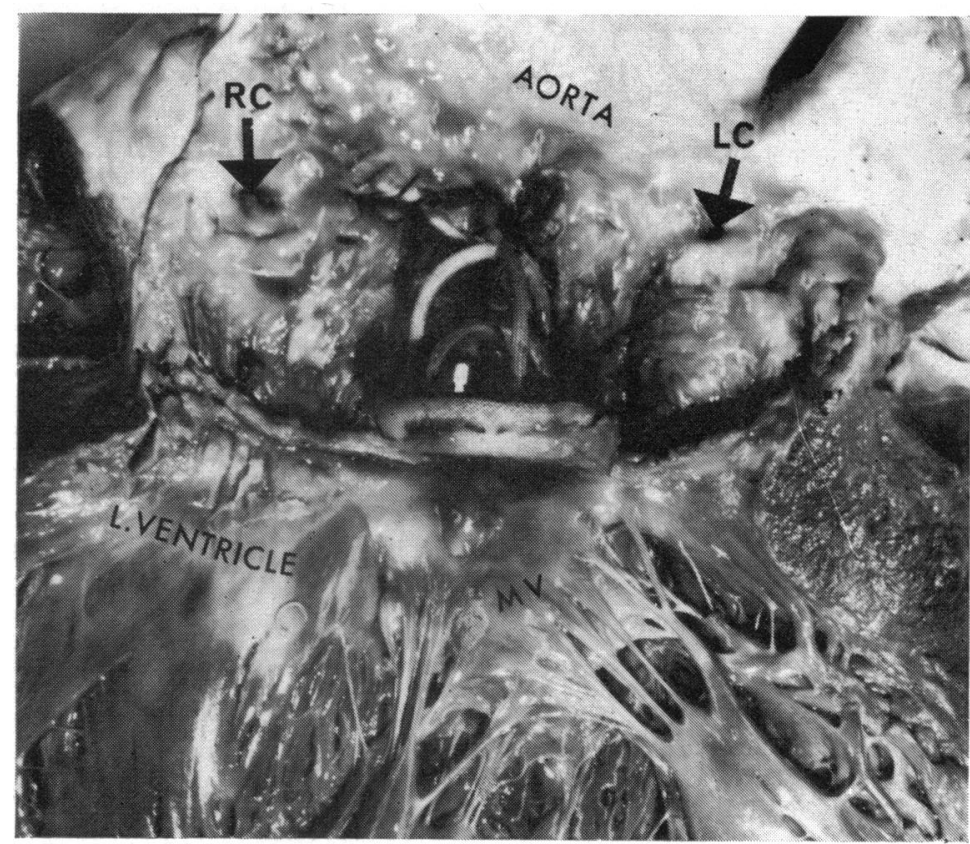

FIG. 4 Necropsy specimen. Left ventricle and aorta opened anteriorly showing prosthetic valve attached only at the non-coronary sinus. Position during systole. $R C$, right coronary orifice; $L C$, left coronary orifice; $M V$, mitral valve.

from which he made a good recovery. A month later he was noted to have an aortic diastolic murmur. Six months after the insertion of the prosthesis, he was readmitted with a two-day

FI . 5 Similar view to Fig. 4. Prosthetic valve is in a diastolic position resting on the underlying aortic leaflet of the mitral valve.

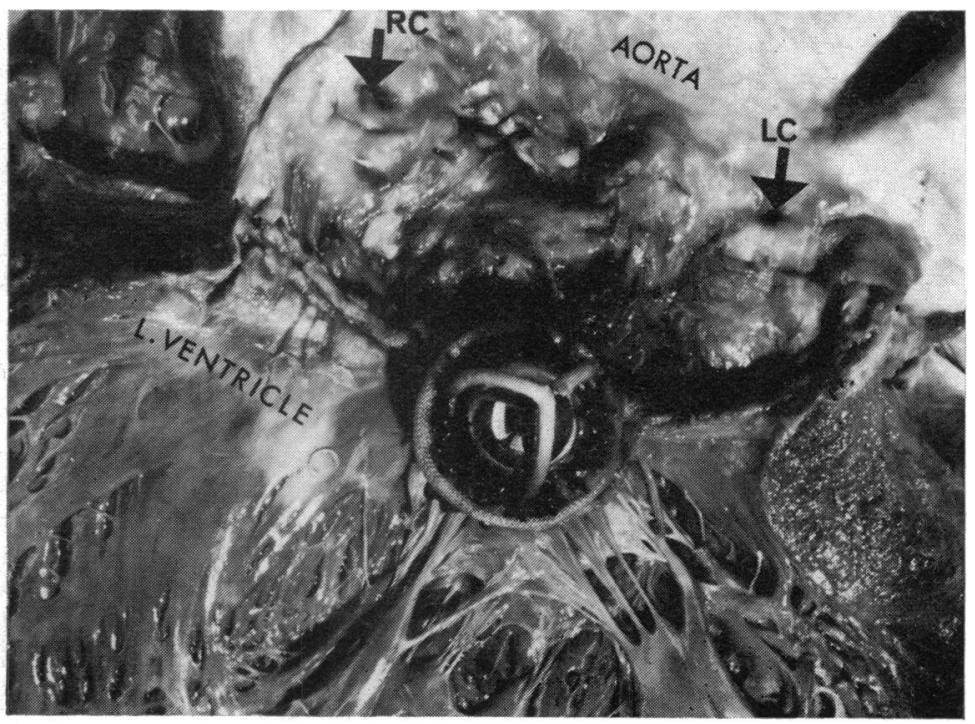




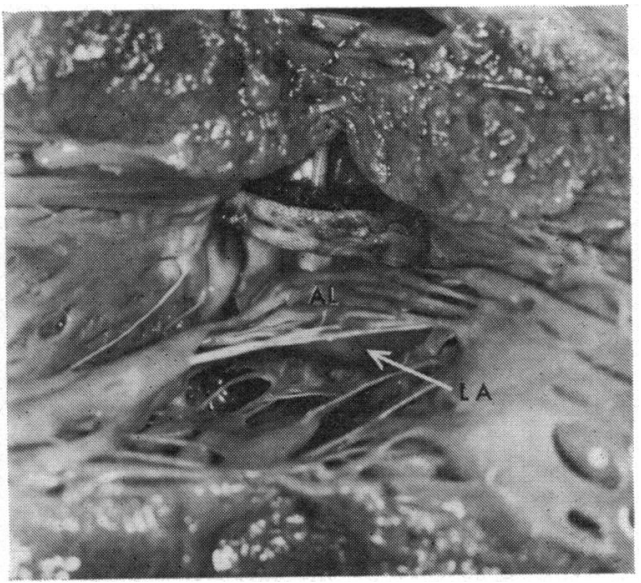

FIG. 6 Left ventricle opened through apex with left atrium $(L A)$ seen through the mitral valve. Prosthetic valve lies transversely across the aortic root resting on the aortic leaflet $(A L)$ of the mitral valve. Position as found at necropsy.

history of chest pain and dyspnoea. On examination, the blood pressure was $120 / 60 \mathrm{~mm}$. $\mathrm{Hg}$ with a sinus tachycardia and a sharp arterial pulse. There were ejection systolic and early diastolic murmurs at the left sternal edge and a mid-diastolic murmur in the mitral area. Chest $x$-ray showed an increase in heart size with dilatation of the upper lobe pulmonary veins and Kerley B-lines. Screening showed pivotal movement of the prosthesis.

At reoperation the prosthesis was found to be detached for two-thirds of its circumference, the area of attachment being the non-coronary sinus region. The sutures had cut out elsewhere. Simultaneous pressures were taken from the left atrium, left ventricle, and aorta before bypass. These records did not show any diastolic gradient between the left atrium and left ventricle. There was a $45 \mathrm{~mm}$. Hg systolic wave in the left atrial pressure tracing. The aortic diastolic pressure was $50 \mathrm{~mm}$. $\mathrm{Hg}$, while the left ventricular enddiastolic pressure was $25 \mathrm{~mm}$. Hg. The prosthesis was replaced with a further No. Io StarrEdwards prosthesis, the ulcerated area being oversewn. His post-operative progress was uneventful, but again an aortic diastolic murmur was noted at two weeks.

Five months later he was readmitted for assessment and thought to have significant aortic regurgitation, with systolic and early diastolic murmurs at the left sternal edge and a blood pressure of $130 / 50 \mathrm{~mm}$. Hg. Screening showed normal movement of the prosthesis. Shortly afterwards he developed sudden chest pain and dyspnoea. He now had a blood pressure of I $10 / 0 \mathrm{~mm}$. $\mathrm{Hg}$, a sharp arterial pulse, and a sinus tachycardia. Apart from the previous auscultatory findings, there was an additional middiastolic murmur in the mitral area. Chest $x$-ray showed an increase in pulmonary congestion with a slight increase in heart size. Screening showed conspicuous pivotal movement of the prosthesis.

At his fourth operation, the prosthesis was again found to be approximately two-thirds detached, in the same area as before, the stitches having cut out. The prosthesis was excised and replaced by a further No. Io Starr-Edwards prosthesis. The patient died five days after operation with a low cardiac output and renal failure. At necropsy, the mitral valve was normal.

\section{Discussion}

Aortic regurgitation around the prosthesis is one of the most common complications following aortic valve replacement with a Starr-Edwards prosthetic valve. The incidence of this complication has been variously reported as 13 per cent (Kastor et al., 1968) and 26 per cent (Wheat et al., I966). Slight aortic regurgitation without significant haemodynamic disturbance and not necessitating further action is the usual situation and has also been reported after aortic valve replacement by aortic homografts (Barratt-Boyes et al., 1965; McDonald et al., 1968). Severe aortic regurgitation is much less common. Kastor et al. (1968) reported that 6 of 203 patients required reoperation for this reason, while in another series 33 of 947 patients with prosthetic valves, of whom II had an aortic prosthesis, required reoperation (Favaloro et al., 1967).

There have been five instances of severe aortic regurgitation in four patients with a Starr-Edwards prosthesis occurring in this hospital out of a total experience of 158 insertions of this prosthesis between 19641968. These five instances had several features in common, which may be present in other patients with severe regurgitation around the aortic valve prosthesis.

Three of our patients had severe calcific aortic stenosis initially. Kastor et al. (1968) noted that all their patients with regurgitation had calcific disease. Favaloro et al. (1967) reported that 8 of II patients with regurgitation had calcific disease and Wheat et al. (1966) reported a similar ratio. The valve ring in this situation is often involved in the calcific process and holds stitches less well as a result. In all our patients the stitches were intact but had pulled out of the heart. Prosthetic valve endocarditis is a severe complication of this kind of operation (Stein, Harken, and Dexter, 1966) and may predispose to the development of leak around the prosthesis (Cohn et al., 1966). One patient (Case 3) had prosthetic valve endocarditis which may have contributed to the detachment of the valve. However, both this 
patient and one other (Case 4) had previous aortic valve replacement, and this may predispose to valve detachment as the suture bed becomes abnormal and does not hold stitches so well.

The time interval between the insertion of the prosthesis and the onset of regurgitation varies. It may, of course, date from the time of operation and is then due to faulty technique. In these patients the prostheses were competent for between three weeks and five months, which is in agreement with the findings of Favaloro et al. (1967) who note that regurgitation can occur at any time during the first two years after operation.

Prosthetic valve regurgitation is recognized by the finding of an early diastolic murmur heard best at the left sternal edge (Bristow et al., 1964). This was heard in all our patients. However, assessment of severity can be more difficult. Conventionally, chronic severe aortic regurgitation with intact left ventricular function is assuiated with a widened pulse pressure and a variable-length early diastolic murmur. In sudden severe aortic regurgitation left ventricular enddiastolic pressure may approach aortic diastolic pressure, resulting in shortening of the diastolic murmur. Indeed, left ventricular end-diastolic pressure may exceed left atrial pressure during diastole, producing premature closure of the mitral valve which gives rise to a sound in late diastole (Meadows et al., 1963; Rees et al., 1964). Though all our patients had sudden severe detachment of the prosthesis, these auscultatory or phonocardiographic characteristics were not noted.

The finding of a mid-diastolic murmur (Flint, I886) in severe aortic regurgitation is well documented, though the precise explanation has been in dispute. Herrmann (1926) noted that a lesion in the posterior cusp of the aortic valve could cause a regurgitant jet into the ventricle so directed as to displace the aortic leaflet of the mitral valve, thereby causing it to impede the left atrial-left ventricular blood flow in diastole. More recently, late diastolic regurgitation from left ventricle to left atrium has been shown in severe aortic regurgitation and postulated as an explanation for the Austin-Flint murmur (Lochaya, Igarashi, and Shaffer, 1967). In addition, an early diastolic gradient with left atrial pressure exceeding left ventricular pressure coinciding with the onset of the murmur in the mitral area has been shown (O'Brien and Cohen, 1969), providing an additional explanation for the Austin-Flint murmur.

Apart from the first patient, in whom no comment was made on auscultation in the mitral area, the patients described here all had mid-diastolic murmurs (Fig. I). In two of these patients simultaneous pressures were measured at operation in the left atrium, left ventricle, and aorta. There was no equilibration of left ventricular and aortic pressures in diastole (Fig. 2), as may be seen in severe aortic regurgitation (Rees et al., 1964; Wigle and Labrosse, 1965). Equally, there were no gradients between left ventricle and left atrium in diastole, so that there was no pressure explanation for the mid-diastolic murmur. However, the left atrial pressure trace was compatible with severe mitral regurgitation by virtue of the tall systolic wave (Raftery et al., 1966), though there was no auscultatory evidence of mitral regurgitation.

We feel that these unusual auscultatory and haemodynamic phenomena may be explained by the nature of the detachment. In all these patients the Starr-Edwards prosthesis was detached for between two-thirds and three-quarters of its circumference. The remaining area of attachment was identical in all patients - in the region of the non-coronary sinus (Fig. 4 and 5). Similar findings (though not invariable) were reported by Favaloro et al. (1967) and Stinson, Castellino, and Shumway (1968). Björk (1966) noted that in a patient with a leaking prosthesis attachment was confined to the non-coronary sinus. He postulated that the weakest area of the aortic root is anterior between the right and left coronary cusps, as there is less elastic tissue in relation to the septum.

Massive detachment of the prosthesis means that it is virtually on a 'hinge'. The 'hinge' is at the root of the aortic leaflet of the mitral valve (Fig. 4). In this position the pivotal movement of the prosthesis interferes with the opening of the aortic leaflet of the mitral valve (Fig. 5, 6, 7b) and may provide the explanation for the mid-diastolic murmur, though no pressure difference was found. Conversely, in systole the prosthesis, attached only posteriorly to the base of the aortic leaflet of the mitral valve, is forced upwards and rotated. This is facilitated by the post-stenotic dilatation of the aorta. Rotation may cause traction on the mitral valve resulting in regurgitation (Fig. $7 \mathrm{a}$ ), as suggested by the left atrial pressure tracings. In all these patients the mitral valve was normal, whereas if it had been diseased it might not have been distorted so readily.

Other clinical findings in this situation were non-specific. The history was dramatic, with sudden chest pain, possibly due to impairment in coronary flow, and acute dyspnoea from pulmonary venous hyper- 

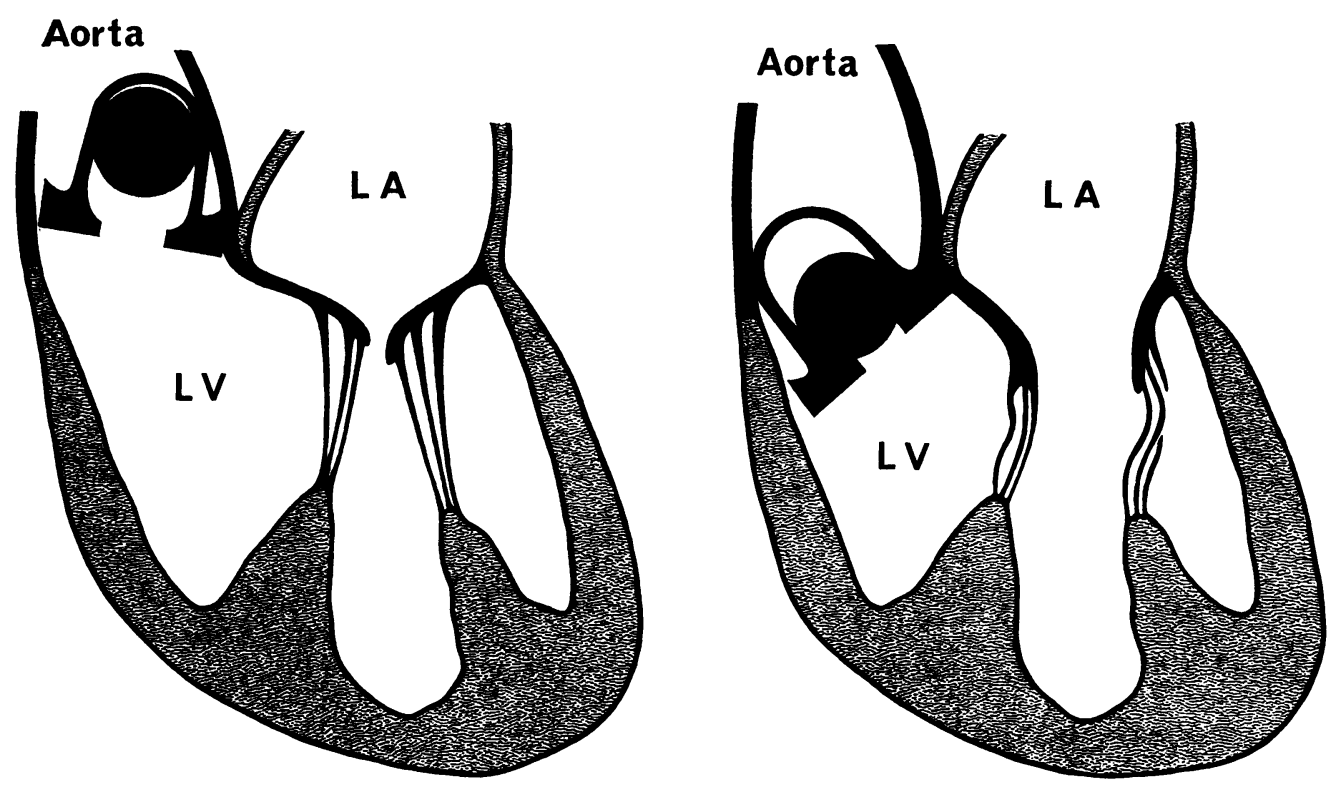

FIG. 7 Diagrammatic representation of pivotal movement of detached prosthetic valve showing positions in systole (left) and diastole (right). $L A$, left atrium; $L V$, left ventricle.

tension, confirmed on chest $x$-rays, which showed dilated upper lobe pulmonary veins, Kerley B-lines, and, in one patient, pleural effusions. The electrocardiogram did not alter, except that one patient presented in complete heart block.

The simplest method of confirming the diagnosis was by cardiac fluoroscopy. In every patient this showed pivotal movement of the prosthesis (Fig. 3), and by recording the motion in more than one plane enabled an accurate diagnosis of the site of the 'hinge'. In a prosthesis fully attached in the aortic site there is very little pivotal movement during the cardiac cycle (Gimenez, Soulen, and Davila, 1968). Thus even minor degrees of movement are significant (Cohn et al., 1966). An alternative method of making the diagnosis is by a double-exposure $x$-ray, which shows significant blurring of a prosthesis which is rocking (Lansing, 1967). In one of our patients (Case 3 ) we were able to compare cinefluoroscopic films before and after detachment, and in another (Case 4) between doubtful minor pivotal movement and major detachment. It may well be valuable to carry out routine cinefluoroscopy of patients with Starr-Edwards prostheses in order to detect minor rocking movement characteristic of detachment.

The mortality in patients with sudden major detachment of a prosthetic valve is high, and many will not survive long enough to allow corrective procedures to be undertaken. Reattachment or replacement of the prosthesis may lead to a subsequent detachment as the sutures may not hold so well in a ring from which stitches have already torn out. This was well illustrated by Case 4, where the same event occurred on two separate occasions, eventually leading to death. None the less, reoperation is the only course available and in Case 2 this proved successful, with no further problems at one-year followup.

We would like to thank Mr. O. S. Tubbs, Mr. M. Paneth, and Dr. R. V. Gibson for their helpful comments.

\section{References}

Barratt-Boyes, B. G., Lowe, J. B., Cole, D. S., and Kelly, D. T. (1965). Homograft valve replacement for aortic valve disease. Thorax, 20, 495 .

Björk, V. O. (1966). Surgical treatment of recurrent aortic insufficiency after aortic valve replacement with the Starr-Edwards ball valve prosthesis. Thorax, 21, 450 .

Bristow, J. D., McCord, C. W., Starr, A., Ritzmann, L. W., and Griswold, H. E. (1964). Clinical and hemodynamic results of aortic valvular replacement with a ball-valve prosthesis. Circulation, 29, Suppl., 36.

Cohn, L. H., Roberts, W. C., Rockoff, S. D., and Morrow, A. G. (1966). Bacterial endocarditis following aortic valve replacement. Circulation, 33, 209.

Favaloro, R. G., Effler, D. B., Groves, L. K., Suarez, E., and Shirey, E. K. (I967). Surgical repair of 
leaking prosthetic heart valves. Annals of Thoracic Surgery, 3, 503.

Flint, A. (1886). The mitral cardiac murmurs. American fournal of the Medical Sciences, 91, 27.

Gimenez, J. L., Soulen, R. L., and Davila, J. C. (1968). Prosthetic valve detachment; its roentgenographic recognition: report of cases. American fournal of Roentgenology, Radium Therapy, and Nuclear Medicine, 103, 595.

Herrmann, G. R. (1926). The Austin Flint phenomenon. An experimental and clinical study. American Heart fournal, r, 671.

Kastor, J. A., Akbarian, M., Buckley, M. J., Dinsmore, R. E., Sanders, C. A., Scannell, J. G., and Austen, W. G. (1968). Paravalvular leaks and hemolytic anemia following insertion of Starr-Edwards aortic and mitral valves. Fournal of Thoracic and Cardiovascular Surgery, 56, 279.

Lansing, A. M. (1967). Unusual radiologic sign of loose mitral valve prosthesis. Radiology, 88, 789.

Lochaya, S., Igarashi, M., and Shaffer, A. B. (1967). Late diastolic mitral regurgitation secondary to aortic regurgitation; its relationship to the AustinFlint murmur. American Heart fournal, 74, 161.

McDonald, A., McDonald, L., Resnekov, L., Robinson, M., and Ross, D. (1968). Homograft replacement of the aortic valve. Immediate results and follow-up. Lancet, 2, 469.

Meadows, W. R., Van Praagh, S., Indreika, M., and Sharp, J. T. (I963). Premature mitral valve closure. A hemodynamic explanation for absence of the first sound in aortic insufficiency. Circulation, 28, 251.

O'Brien, K. P., and Cohen, L. S. (1969). Hemodynamic and phonocardiographic correlates of the Austin-Flint murmur. American Heart fournal, 77, 603 .

Raftery, E. B., Oakley, C. M., and Goodwin, J. F. (1966). Acute subvalvar mitral incompetence. Lancet, 2, 360.

Rees, J. R., Epstein, E. J., Criley, J. M., and Ross, R. S. (1964). Haemodynamic effects of severe aortic regurgitation. British Heart fournal, 26, 412.

Roberts, W. C., Braunwald, E., and Morrow, A. G. (1966). Acute severe mitral regurgitation secondary to ruptured chordae tendineae. Circulation, 33, 58.

Stein, P. D., Harken, D. E., and Dexter, L. (1966). The nature and prevention of prosthetic valve endocarditis. American Heart fournal, 71, 393.

Stinson, E. B., Castellino, R. A., and Shumway, N. E. (1968). Radiologic signs in endocarditis following prosthetic valve replacement. Fournal of Thoracic and Cardiovascular Surgery, 56, 554.

Wheat, M. W., Jr., Linhart, J. W., Bartley, T. D., Taylor, W. J., Crevasse, L. E., and Green, J. R., Jr. (1966). Aortic ball-valve (Starr-Edwards) prostheses. A follow-up evaluation. Annals of Thoracic Surgery, 2, 166.

Wigle, E. D., and Labrosse, C. J. (1965). Sudden, severe aortic insufficiency. Circulation, 32, 708. 